\title{
Differing responses of red abalone (Haliotis rufescens) and white abalone ( $H$. sorenseni) to infection with phage- associated Candidatus Xenohaliotis californiensis
}

\author{
Ashley Vater ${ }^{\text {Corresp., }}{ }^{1}$, Barbara A Byrne ${ }^{2}$, Blythe C Marshman ${ }^{3}$, Lauren W Ashlock ${ }^{3}$, James D Moore ${ }^{3,4}$ \\ 1 Integrative Pathobiology Graduate Group, University of California, Davis, Davis, United States \\ 2 Pathology, Microbiology, Immunology, School of Veterinary Medicine, University of California, Davis, Davis, United States \\ 3 Shellfish Health Laboratory, California Department of Fish and Wildlife, Bodega Bay, United States \\ 4 Karen C. Drayer Wildlife Health Center, School of Veterinary Medicine, University of California, Davis, Davis, United States \\ Corresponding Author: Ashley Vater \\ Email address: awvater@ucdavis.edu
}

The Rickettsiales-like prokaryote and causative agent of Withering Syndrome (WS) Candidatus Xenohaliotis californiensis ( $\mathrm{Ca}$. Xc) - decimated black abalone populations along the Pacific coast of North America. White abalone, - Haliotis sorenseni - are also susceptible to WS and have become nearly extinct in the wild due to overfishing in the 1970s. Candidatus Xenohaliotis californiensis proliferates within epithelial cells of the abalone gastrointestinal tract and causes clinical signs of starvation. In 2012, evidence of a putative bacteriophage associated with $\mathrm{Ca}$. Xc in red abalone - Haliotis rufescens - was described. Recently, histologic examination of animals with $\mathrm{Ca}$. Xc infection in California abalone populations universally appear to have the phage-containing inclusions. In this study, we investigated the current virulence of $\mathrm{Ca}$. Xc in red abalone and white abalone at different environmental temperatures. Using a comparative experimental design, we observed differences over time between the two abalone species in mortality, body condition, and bacterial load by quantitative real time PCR (qPCR). By day 251, all white abalone exposed to the current variant of $\mathrm{Ca}$. Xc held in the warm water $\left(18.5^{\circ} \mathrm{C}\right)$ treatment died, while red abalone exposed to the same conditions had a mortality rate of only $10 \%$, despite a relatively heavy bacterial burden as determined by qPCR of posterior esophagus tissue and histological assessment at the termination of the experiment. These data support the current status of $\mathrm{Ca}$. Xc as less virulent in red abalone, and may provide correlative evidence of a protective phage interaction. However, white abalone appear to remain highly susceptible to this disease. These findings have important implications for implementation of a white abalone recovery program, particularly with respect to the thermal regimes of locations where captively-reared individuals will be outplanted. 
1 Differing responses of red abalone (Haliotis rufescens) and white abalone (H. sorenseni) to

2 infection with phage-associated Candidatus Xenohaliotis californiensis

3

4 Ashley Vater $^{1}$

5 Barbara A. Byrne ${ }^{2}$

6 Blythe C. Marshman ${ }^{3}$

7 Lauren W. Ashlock ${ }^{3}$

8 James D. Moore 3,4

9

$10{ }^{1}$ Integrative Pathobiology Graduate Group, University of California, Davis, Davis CA 95616

11 2Pathology, Microbiology, Immunology, School of Veterinary Medicine, University of

12 California, Davis, Davis CA 95616

$13{ }^{3}$ Shellfish Health Laboratory, California Department of Fish and Wildlife, Bodega Bay, CA

1494923

$15{ }^{4}$ Karen C. Drayer Wildlife Health Center, School of Veterinary Medicine, University of

16 California, , Davis CA 95616

17 Corresponding Author:

18 Ashley Vater

19 Email address: awvater@ucdavis.edu 


\section{ABSTRACT}

The Rickettsiales-like prokaryote and causative agent of Withering Syndrome (WS) Candidatus Xenohaliotis californiensis $(\mathrm{Ca} . \mathrm{Xc})$ - decimated black abalone populations along the Pacific coast of North America. White abalone, - Haliotis sorenseni - are also susceptible to WS and have become nearly extinct in the wild due to overfishing in the 1970s. Candidatus Xenohaliotis californiensis proliferates within epithelial cells of the abalone gastrointestinal tract and causes clinical signs of starvation. In 2012, evidence of a putative bacteriophage associated with $C a$. Xc in red abalone - Haliotis rufescens - was described. Recently, histologic examination of animals with $\mathrm{Ca}$. Xc infection in California abalone populations universally appear to have the phage-containing inclusions. In this study, we investigated the current virulence of $\mathrm{Ca}$. Xc in red abalone and white abalone at different environmental temperatures. Using a comparative experimental design, we observed differences over time between the two abalone species in mortality, body condition, and bacterial load by quantitative real time PCR (qPCR). By day 251, all white abalone exposed to the current variant of $C a$. Xc held in the warm water $\left(18.5^{\circ} \mathrm{C}\right)$ treatment died, while red abalone exposed to the same conditions had a mortality rate of only $10 \%$, despite a relatively heavy bacterial burden as determined by qPCR of posterior esophagus tissue and histological assessment at the termination of the experiment. These data support the current status of $\mathrm{Ca}$. Xc as less virulent in red abalone, and may provide correlative evidence of a protective phage interaction. However, white abalone appear to remain highly susceptible to this disease. These findings have important implications for implementation of a white abalone recovery program, particularly with respect to the thermal regimes of locations where captively-reared individuals will be outplanted.

\section{INTRODUCTION}


43 Abalone are iconic benthic invertebrates that contribute to ecological health of northern Pacific

44 coast kelp forests and serve as a food source for endangered sea otters Enhydra lutris.

45 California's wild abalone fishery flourished from the 1950s-1980s but was decommercialized in

46 response to population declines from overexploitation followed by disease (CDFGMR 2005).

47 Farmed abalone is of increasing economic significance; in 2008, it was estimated that over

48129,000 metric tons of farmed abalone was supplied to the world market (Cook 2016).

49

Withering syndrome (WS) was first reported in mid-1980's at the Channel Islands, California and decimated black abalone - Haliotis cracherodii - populations (Haaker et al. 1992). The infection causes reduced feeding behavior and nutrient absorption; animals wither as they lose body mass through catabolism of the foot muscle (Gardner et al. 1995). The causative agent of the disease, Candidatus Xenohaliotis californiensis $(C a . \mathrm{Xc})$ is a member of the Order Rickettsiales of the Alphaproteobacteria (Friedman et al. 2000). Analysis of five genes (16S rRNA, 23S rRNA, ftsZ, vVirB11, and $v$ VirD4) suggested that $C a$. Xc is most closely related to the Neorickettsia genus and is the most ancestral form of the Anaplasmataceae family studied to data (Cicala et al. 2017b). Transmission of Ca. Xc appears to be fecal-oral (Moore et al. 2001). $C a . \mathrm{Xc}$ infects the luminal epithelium of the posterior portion of the esophagus (PE) and digestive gland (Moore et al. 2001). The Ca. Xc bacterium forms large oblong inclusions in the digestive tract epithelium, which are easily identifiable in hematoxylin- and eosin-stained tissue sections (Friedman et al. 2000).

In red abalone, $H$. rufescens, exposure to warm water events in the presence of $\mathrm{Ca}$. Xc exacerbates morbidity and mortality in two synergistic ways: it reduces the nutritional content of their primary food source, and is associated with elevated pathogen burdens (Vilchis et al. 2005). Trends of increasing frequency and intensity of Pacific ocean warming El-Nino events 
66 correspond to dramatic reductions in giant kelp densities (Tegner et al. 1996), and nitrogen

67 nutrient concentration in seawater is inversely related to temperature (Tegner et al. 2001).

68 Furthermore, ocean warming trends coincide with $\mathrm{Ca}$. Xc disease outbreaks (Harvell et al. 1999).

69 The results of laboratory studies using juvenile farm-raised red abalone showed that $\mathrm{Ca}$. Xc has

70 relatively little effect on the health of abalone held at temperatures of approximately $14^{\circ} \mathrm{C}$, while

71 animals held in water approximately $18^{\circ} \mathrm{C}$ suffer high mortality rates in association with higher

72 Ca. Xc body burdens (Braid et al. 2005; Moore et al. 2000; Rosenblum et al. 2005; Vilchis et al.

73 2005). Braid et al. (2005) demonstrated that clinical signs of withering syndrome are not solely

74 due to warm water stress..

75 White abalone $-H$. sorenseni - health and fitness is best supported by a consistent $14^{\circ} \mathrm{C}$

76 seawater environment as determined by optimization of captive breeding methods (Leighton

77 1972; Rogers-Bennett et al. 2016). Increased seawater temperatures are associated with adverse

78 health effects in white abalone that translate to population instability. For example, white

79 abalone spawning success rates are significantly decreased in warm water $\left(20^{\circ} \mathrm{C}\right)$. Ocean

80 warming events have the potential to powerfully exacerbate disease, particularly in the sensitive

81 white abalone species, while simultaneously reducing general animal fitness. White abalone

82 were the first marine invertebrate species to be recognized as federally endangered. Outplanting

83 animals bred and raised in a captive rearing program is considered the key restoration approach

84 to increase densities quickly enough to reduce the probability of extinction (Rogers-Bennett et al.

85 2016; Stierhoff et al. 2014). White abalone are highly susceptible to WS (Friedman et al. 2007).

86 This and globally increasing sea water temperatures may challenge future outplanting efforts. 
88 After the catastrophic population declines reported in the early 90's, wild black abalone survival

89 rates began improving in 1996 which could not be fully attributed to ocean cooling trends that

90 repress expression of WS (Chambers et al. 2005; Chambers et al. 2006). Further, anecdotal

91 observations from California red abalone farmers beginning in 2006 indicated that the incidence

92 and severity of WS had diminished; this change correlated with the appearance of a novel

93 bacteriophage hyperparasite associated with $\mathrm{Ca}$. Xc (Crosson et al. 2014; Friedman \& Crosson

94 2012). This bacteriophage was first described in farmed red abalone from Cayucos, California

95 examined in 2009 (Friedman \& Crosson 2012). Its presence was visualized by histology as

96 morphologically distinct inclusions and transmission electron microscopy (TEM) confirmed the

97 presence of phage particles in several studies. These distinct pleomorphic inclusions,

98 independent from confirmatory TEM, are currently recognized as representing phage-containing

99 Ca. Xc (Brokordt et al. 2017; Crosson et al. 2014; González et al. 2014). Further characterization

100 suggests this phage is a member of the Siphoviridae family and employs a lytic life cycle, which

101 results in lysis of the host cell and replicates its genetic material separately from that of the host

102 (Cruz-Flores \& Cáceres-Martínez 2016).

103 Bacteriophages are more abundant than any other marine biological entity; however, there are

104 only a relatively small number of published genomes. These likely fail to capture the high

105 diversity of marine phages (Perez Sepulveda et al. 2016). In April 2018, the annotated genome of

106 the $\mathrm{Ca}$. Xc phage was published and represents the first phage of a marine rickettsial-like

107 organism to be sequenced; the identified open reading frames had low levels of similarities to

108 other known biological entities (Cruz-Flores et al. 2018).

109 While Friedman et al. (2014) demonstrated significant improvement in black abalone survival

110 when challenged with phage-containing $C a$. Xc, the mechanism by which the phage reduces 
111 pathogenicity is unclear. Complex host-pathogen-phage interactions and resulting selective

112 pressures, which increase bacterial resistance to the phage and simultaneously diminished the

113 bacteria's virulence, have been observed in other microbial systems (León \& Bastías 2015).

114 Evidence supports prophage-associated changes in virulence in other Rickettsiales (Masui et al.

115 2000). Mechanisms for variation in $\mathrm{Ca}$. Xc virulence unrelated to phage have been explored in

116 recent years. A preliminary study investigating effects of breeding found that there is a genetic

117 component to Ca. Xc infection susceptibility (Brokordt et al. 2017). Interbreeding between

118 abalone species has been show to transfer susceptibility to WS (González et al. 2014). Heritable

119 and environmental variables may also influence the abalone host microbiome, which is

120 generating interest as a possible factor associated with abalone health and resistance to withering

121 syndrome (Cicala et al. 2017a; Connelly et al. 2012).

122 In this study, we aimed to elucidate changes in $C a$. Xc virulence in association with phage

123 presence on WS expression in red and white abalone species under thermal conditions that are

124 known to either enhance or retard expression of the disease.

\section{MATERIALS AND METHODS}

126 Abalone and Life Support. This experiment was conducted in the California Department of

127 Fish and Wildlife's Pathogen Containment Facility at the UC Davis Bodega Marine Laboratory

128 in Bodega Bay, California. Red abalone, approximately $2.2 \mathrm{~cm}$ in shell length, were purchased

129 from an abalone farm in Goleta, California. White abalone, approximately $1.8 \mathrm{~cm}$ in shell length,

130 were donated from the UC Davis Bodega Marine Laboratory's White Abalone Recovery Project.

131 Prior to challenge, feces from all tanks were tested for 16S rRNA $\mathrm{Ca}$. Xc genes by quantitative

132 PCR (qPCR) following a validated protocol (Friedman et al. 2014b). Although fecal qPCR is

133 treated only as a proxy for live pathogen, it has been shown to be the most sensitive assay for $C a$. 
134 Xc detection (Friedman et al. 2014b). To support the absence of infection, five animals from

135 both the red and white groups were sacrificed for histologic examination. Animals were supplied

136 with a combination of wild-collected kelp (Macrocystis pyrifera) and cultured dulse (Palmaria

137 palmata) two to three times per month throughout the experiment. Because $\mathrm{Ca}$. Xc is known to

138 be present in local abalone, feed was soaked in freshwater for at least 5 minutes prior to

139 distributing to the tanks; our ongoing unpublished observations have demonstrated that this is

140 sufficient to inactivate residual $\mathrm{Ca}$. Xc that may be present on algal feed (CDFW unpublished

141 observations). All tanks received constant 20- $\mu \mathrm{m}$ filtered, aerated, UV-irradiated, flow-through

142 seawater.

143 Experimental design. This study was constructed as a fully nested design with tanks nested

144 within temperatures and $\mathrm{Ca}$. Xc exposure challenge and abalone nested within tanks. One

145 hundred ninety-two red and 192 white abalone, $\sim 2 \mathrm{~cm}$ in length, were randomly and evenly

146 distributed into either of the two treatment groups (exposed), or the control group (Figure 1).

147 To avoid cross-contamination, we spatially organized the groups in lieu of random placing. Each

148 treatment group was comprised of eight 3.8-L tanks, with eight animals housed in each tank.

149 Two groups, one exposed to $C a$. Xc and the other unexposed, received elevated temperature

150 seawater (approximately $18.5^{\circ} \mathrm{C}$ ); a second $\mathrm{Ca}$. Xc-exposed group received ambient water

151 (approximately $13.6^{\circ} \mathrm{C}$ ). Temperature was measured hourly by automated temperature recorder

152 placed in one tank per treatment group.

153 Exposure to $\boldsymbol{C a}$. Xc. To initiate $C a$. Xc exposure, inflowing seawater was routed through 11-L

154 conical header tanks with farmed red abalone prior to supplying the experimental tanks. The two

155 exposed groups of each species received effluent water from a header tank containing eight

156 farmed red abalone, each approximately $123 \mathrm{gm}$ in weight, from a population shown by 
157 histology to be infected with $C a$. Xc and its phage. The control groups of red abalone and white

158 abalone were headed by a tank holding 50 farmed red abalone, approximately 2.4 gm in weight;

159 these animals' feces tested negative for $\mathrm{Ca}$. Xc by PCR. The source water was directed through

160 the headers through day 161 to ensure $\mathrm{Ca}$. Xc exposure. Moore et al. (2001) showed that

161 infection in red abalone was $100 \%$ after 111 days of $C a$. Xc exposure to a header tank with

162 infected red abalone at $18.5^{\circ} \mathrm{C}$ (prior to appearance of the $\mathrm{Ca}$. Xc phage).

163 Sampling schedule and processing. At selected time points (days 0, 62, 126, 161, 265, 343) all

164 animals in the experiment were weighed and measured for shell length. A body mass Condition

165 Index (CI) was calculated as: $\frac{\text { Total Weight }(\mathrm{gm})}{\text { Shell Length }(\mathrm{cm})^{3}}$. At day 161, header tanks were removed and two

166 randomly selected animals per tank were sacrificed and tested for $C a$. Xc infection by qPCR

167 from DNA extracted from post-esophagus (PE) tissue samples. Additionally, at day 161, six

168 white abalone, three animals each from the heated and ambient exposed groups, were randomly

169 selected and sacrificed for histological confirmation of transmission of $\mathrm{Ca}$. Xc and its phage. At

170 day 343, all surviving experimental animals were processed for analysis of infection in PE and

171 digestive gland tissues by both qPCR and histology. For qPCR, PE tissue ( $\sim 30 \mathrm{mg})$ was excised

172 from sacrificed animals and DNA extractions were performed using a DNeasy Blood and Tissue

173 Kit (QIAGEN Germantown, MD) following the manufacturer's protocol for pathogen detection.

174 Tissue samples were processed for histology as previously described (Moore et al. 2001).

175 Davidson's-fixed (Shaw and Battle 1957), hematoxylin- and eosin-stained $5 \mu \mathrm{m}$ paraffin tissue

176 sections containing PE and digestive gland were prepared from sacrificed animals. After

177 termination of the experiment, slides were blindly assessed for presence/absence of $\mathrm{Ca}$. Xc

178 inclusions, and the inclusions present were categorized as having morphologies indicating phage

179 infection (phage-containing) or lack of infection (classical). 
180 Fecal bacterial sampling regimen and processing. Feces were collected from each tank bi181 monthly for qPCR analysis. Feces from four tanks per group were pooled for $\mathrm{Ca}$. Xc $16 \mathrm{~S}$ rRNA 182 gene detection. Fecal samples were weighed and frozen at $-20{ }^{\circ} \mathrm{C}$ upon collection until analysis. 183 DNA from fecal samples ( 250mg) was extracted and purified with a QIAamp DNA Stool Mini

184

185

186

187

188

189

190

191

192

193

194

195

196

197

198

199

200

201

202

Kit (QIAGEN) according to the manufacturer's 'Isolation of DNA from Stool for Pathogen

Detection' protocol. DNA obtained was eluted in $200 \mu \mathrm{l}$ volumes and stored at $-20^{\circ} \mathrm{C}$ until analysis.

Quantitative PCR assays for $\boldsymbol{C a}$. Xc. We monitored $C a$. Xc gene presence in post-esophagus and fecal samples using the methods developed and validated by Friedman et al (2014). Standard curves were constructed using PCR product of the WSN1 primers: WSN1 F (5'AGTTTACTGAAGGCAAGTAGCAGA3') and WSN1R (5'TCTAAC TTGGACTCATTCAAAAGC3') and the P16RK3 plasmid (Friedman et al. 2014b). Plasmid concentration was quantified by Qubit fluorometer (ThermoFisher Scientific, Waltham, Massachusetts). Assayed tissue and fecal samples were considered positive if the mean copy number per ng of genomic DNA in triplicate samples was equal to or greater than one, and reactions prior to normalization calculations had at least three gene copies - as convention of Minimum Information for Publication of Quantitative Real-Time PCR Experiments guidelines describes (Bustin et al. 2009). For reporting purposes, and to meet assumption of residual normality for statistical analysis, reaction copy numbers were normalized by input DNA (ng) and $\log$ transformed.

Data analysis. A Cox proportional hazard model was used for survival analysis of treatment groups. A Chi-squared test was used to assess differences in survival of red abalone between this study and a historical study conducted prior to presence of the phage (Moore et al. 2000). Hazard 
203 ratio terminology refers to the likelihood of death associated with stratified variables: species,

204 water temperature, $C a$. Xc exposure. Variations in (1) condition index values and (2) qPCR data,

205 were tested for significance by One-way ANOVA. Results of these models were assessed by

206 post hoc Tukey comparisons; results are reported with estimates and standard deviations,

207 describing the difference of the means and variance respectively from null hypothesis of the

208 linear model. Residual errors from analysis were assessed for normality using the Wilk Shapiro

209 test. Data from qPCR study was log-transformed. Both log-transformed qPCR data and condition

210 index data was transformed by winsorization to meet the parametric test assumptions of

211 normality. A test had a significant result if $\mathrm{p} \leq 0.05$ (level of significance $\alpha=0.05$ ). Statistical

212 analysis was done with R version X R3.1.3 (R Core Team 2014).

\section{RESULTS}

214 Transmission of $\boldsymbol{C a}$. Xc. All $\mathrm{Ca}$. Xc-exposed groups showed fecal shedding of $\mathrm{Ca}$. Xc DNA

215 after header tank removal from the system (day 161), indicating effective transmission to the

216 exposed red abalone and white abalone under both temperature regimes. The unexposed tanks

217 tested negative by feces PCR (Table 1).

218 Pathogen transmission to all $\mathrm{Ca}$. Xc-exposed tanks was confirmed by tissue qPCR from animals

219 sacrificed at the end of the experiment with the exception of the $C a$. Xc-exposed, elevated

220 temperature white abalone which all died prior to day 343. Abalone that died of natural causes

221 during the experiment were frozen and PE was excised and screened by qPCR for $\mathrm{Ca}$. Xc. Of

222 these animals, 16\% from the control groups produced very low levels of $\mathrm{Ca}$. Xc gene

223 amplification ( $<$ three copies/ng input DNA). The source of the potential contamination is

224 unknown. Other measurements from fecal qPCR, tissue qPCR from sacrificed animals, and

225 histology assessments did not indicate transmission of $\mathrm{Ca}$. Xc. to the control groups. 
226 Analysis of survival. We examined survival in response to water temperature, abalone species,

227 and $C a$. Xc exposure (Figure 2).

228 Our analysis indicated that white abalone exposed to $C a$. Xc and elevated temperature were 10.9

229 times more likely to die than red abalone held in the same conditions (hazard ratio $=10.9 ; 95 \%$

$230 \mathrm{CI}=5.97-19.87 ; \mathrm{P}<0.001)$. By day 251, all $\mathrm{Ca}$. Xc-exposed white abalone in the elevated

231 temperature treatment died, while red abalone held under the same conditions maintained a

232 survival rate of $91 \%$. Elevated temperature increased mortality risk for both red and white

233 abalone 3.3 times that of the ambient treatment groups (hazard ratio $=3.3 ; 95 \% \mathrm{CI}=1.1-10.2$;

$234 \mathrm{P}=0.039)$. Specifically, under elevated temperature, $\mathrm{Ca}$. Xc-exposure increased the mortality risk

235 of both species of abalone 12.5 times (hazard ratio $=12.5 ; 95 \% \mathrm{CI}=1.6-96.0 ; \mathrm{P}=0.015$ ).

236 Generally, under all conditions, white abalone had a risk of mortality that was 41 times that of

237 red abalone (hazard ratio $=41.0 ; 95 \% \mathrm{CI}=5.6-303.1 ; \mathrm{P}<0.001)$.

238 The survival rate of red abalone in the current study, exposed to $C a$. Xc with phage, was $36 \%$

239 higher than the previous experiment, in which animals were exposed to phage-free $\mathrm{Ca}$. Xc

240 (Table 2) (Moore et al. 2000). We evaluated survival at day 220, immediately prior to

241 termination day in the 2000 study (Moore et al. 2000). Between Days 1 and 220, in both

242 experiments, the average water temperature was $18.5^{\circ} \mathrm{C}$ (Moore et al. 2000). Both experiments

243 used farm-origin juvenile red abalone. The 60 animals in the 2000 study averaged $8 \mathrm{~cm}$ in length

244 and were selected from a farmed population with a known low-intensity $\mathrm{Ca}$. Xc infection;

245 however, this population did not express clinical symptoms of WS (Moore et al. 2000).

246 Comparison of survival in the historical (phage-free) and current (phage-containing)

247 experimental data by Chi-squared test shows a significant difference $(X$-squared $=25.37, \mathrm{df}=1$,

$248 \mathrm{P}<0.001)$ favoring survival in the presence of phage. 
249 Body condition indices. Assessment of animal health - as a function of weight, normalized by

250 length - over time showed that red abalone remained heathy under all experimental conditions,

251 unlike their white abalone counterparts (Figure 3).

252 While data were collected at additional time points, we focused on three - beginning, mid, and

253 end - for visual clarity. At the outset of the experiment (Day 0), the only group that showed a

254 significant difference in CI values was the white, ambient group destined for $\mathrm{Ca}$. Xc exposure,

255 with a greater condition index values than the other five groups (Estimate 0.008, Std. Error

2560.002 , t-value=3.950, $\mathrm{P}<0.001$ ). Mid-way through the experiment (Day 161) all three groups of

257 white abalone overall had lower mean condition index values than their red counterpart groups.

258 Statistical analysis showed significant differences between control, elevated temperature red and

259 white groups (Estimate -0.009 , Std. Error 0.003, t-value=-3.497, $\mathrm{P}<0.007$ ) with somewhat

260 greater differences between the exposed red and white groups in both elevated temperature

261 (Estimate -0.020, Std. Error 0.003, t-value=-6.003, $\mathrm{P}<0.001$ ) and ambient (Estimate -0.017, Std.

262 Error 0.003, t-value $=-6.459, \mathrm{P}<0.001$ ) seawater treatments. However, no differences were

263 observed between elevated temperature and ambient white, $C a$. Xc-exposed groups (Estimate -

2640.008 , Std. Error 0.003, t-value=-2.386, $\mathrm{P}=0.162$ ) although more than half of the exposed

265 elevated temperature white abalone had died prior to this time point. Based on visualization of

266 longitudinal changes, white abalone fared worse under all treatments; $\mathrm{Ca}$. Xc exposure appeared

267 to be associated with increased withering in white abalone, while red abalone did not appear to

268 decrease in body condition in response to $\mathrm{Ca}$. Xc exposure. At the end of the experiment (day

269 343), white and red abalone under the same treatment of $\mathrm{Ca}$. Xc-exposure in ambient seawater

270 showed significant differences in body condition (Estimate -0.024, Std. Error 0.004, t-value=-

$2715.823, \mathrm{P}<0.001)$. However, we observed significant, yet smaller differences between the control 
272 groups (Estimate -0.013 , Std. Error 0.004, t-value=-3.242, $\mathrm{P}<0.0121$ ). There was not a

273 significant difference in white abalone body condition between the control and $\mathrm{Ca}$. Xc-exposed,

274 ambient, groups (Estimate 0.004, Std. Error 0.005, t-value=0.955, $\mathrm{P}=0.872$ ); additionally, there

275 was no difference between red abalone in the control and the exposed, elevated temperature

276 groups (Estimate 0.001, Std. Error 0.003, t-value=0.369, $\mathrm{P}=.996$ ).

277 Candidatus Xc prevalence and infection intensity. Candidatus Xc 16S rRNA gene copy

278 numbers obtained by qPCR from PE tissue can serve as a proxy for bacterial burden, and were

279 assessed at days 161 and 343 (Figure 4).

280 The qPCR data from tissue samples taken on day 161 were too skewed to transform such that

281 residuals met normality assumptions for appropriate parametric statistical analysis. However,

282 visualization of data trends suggests that at day 161, elevated temperature resulted in higher

283 pathogen tissue burdens in white abalone (Figure 4); the mean $\mathrm{Ca}$. Xc gene copy number per ng

284 DNA from tissue samples of exposed white abalone in the elevated temperature regimen was

2854 4,248; 326 times greater that of their red counterparts. Notably, white animals sacrificed at this

286 time point were survivors $-60 \%$ of their cohort already died. There was no $\mathrm{Ca}$. Xc

287 amplification in the red, exposed ambient group at day 161. At day 343, red abalone in the

288 exposed, ambient group had significantly lower pathogen gene numbers than (a) the exposed

289 elevated temperature red group (Estimate 2.485, Std. Error 0.3167, t-value=7.845, P<0.001) and

290 (b) their exposed, ambient white counterparts (Estimate 2.045, Std. Error 0.3167, t-value=6.475,

$291 \mathrm{P}<0.001)$. No $C a$. Xc DNA was amplified from PE tissue samples of sacrificed animals in the

292 unexposed groups at either time point.

293 At day 161, three white abalone from each of the exposed ambient and exposed elevated

294 temperature groups were sacrificed and used for histopathology to corroborate transmission data 
295 from fecal and tissue qPCR samples and determine whether any $\mathrm{Ca}$. Xc inclusions present

296 included those with morphology indicating phage infection. For the first time, we

297 morphologically identified the phage-containing inclusions in white abalone (Figure 5).

298 Histological examination of day 343 samples showed the presence of $\mathrm{Ca}$. Xc classical inclusions

299 and phage-containing inclusions in the red, elevated temperature and white, ambient temperature

300 groups (Table 3). In concordance with the qPCR data, we observed nearly three times as many

301 classical inclusions and more than five times as many phage-containing inclusions in post-

302 esophagus samples from the exposed red, elevated temperature group compared to the exposed

303 white, ambient group. Candidatus Xc inclusions (both classical and phage-containing) in

304 digestive gland tissue were only observed in the $C a$. Xc-exposed, elevated temperature, red

305 abalone group.

306 DISCUSSION

307 The initial goal of this study was to investigate potential diminished pathogenicity of $\mathrm{Ca}$. Xc in

308 association with phage presence. However, the clear differences in expression of WS between

309 white and red species is a key and unexpected finding. The white abalone control group was

310 adversely affected by the heated seawater - as observed by body condition and survival of the

311 control group - perhaps contributing evidence for the frailty of the species. White abalone,

312 exposed to $\mathrm{Ca}$. Xc and held in $18.5^{\circ} \mathrm{C}$ seawater, exhibited the highest mortality rate and most

313 pronounced clinical signs of withering syndrome among the experimental groups, thus appearing

314 to be highly susceptible to WS infection and disease, even with current phage-presence.

315 However, under conditions that previously had been shown to exacerbate disease, the effects of

316 WS from the current variant of $C a$. Xc in association with the phage are reduced in red abalone

317 relative to a similar study conducted more than a decade beforehand when no phage was evident. 
318 Transmission of $\mathrm{Ca}$. Xc was slowest in the red, ambient group based on fecal and tissue qPCR

319 values. Variables that influenced fecal production and degradation, primarily feeding schedule,

320 impaired normalization and thus interpretation accuracy of qPCR quantitative data, and therefore

321 Table 1 summarizes only the presence/absence of $C a$. Xc genes. Although, previous work has

322 demonstrated PCR to be the most sensitive $\mathrm{Ca}$. Xc detection method, it should be mentioned that

323 due to assay sensitivity limitations, contamination in the control groups may have gone

324 unidentified. In accordance with our results, slow infection progression in cold water has been

325 show in previous studies (Braid et al. 2005; Moore et al. 2000). While the Moore et al. 2000

326 study identified $\mathrm{Ca}$. Xc inclusions in $90 \%$ of experimental animals held at ambient temperature

$327\left(14.7^{\circ} \mathrm{C}\right)$ at day 220 , in the current study no inclusions were found by histology in the exposed

328 red abalone held at $13.6^{\circ} \mathrm{C}$ sacrificed on day 343 . This finding from the 2000 study may be the

329 result of 'natural' farm-associated transmission at a time point prior to the start of the study but it

330 may also be indicative of a more virulent $C a$. Xc strain. Additionally, the small histology

331 subsample taken at day 161 from white abalone, held under ambient conditions did not have

332 inclusions. We speculate that phage presence may also have extended the disease incubation

333 period in the ambient temperature groups.

334 From weight and length data, we can infer that both the white and red abalone destined for $\mathrm{Ca}$.

335 Xc-exposure and elevated temperature treatment started with robust body condition, and thus

336 were not at a disadvantage that would have predisposed them to withering and death. The

337 similarity between the elevated temperature, control and ambient exposed white groups' survival

338 curves and condition index values supports the general sensitivity of these animals to adverse

339 conditions and may also be a result of low genetic diversity (Gruenthal \& Burton 2005). The

340 pronounced effects of temperature may be explained by white abalone's natural habitat; they are 
341 a deeper-dwelling species and experience less fluctuation in water temperature than other species

342 that inhabit intertidal and shallower subtidal zones.

343 In order to examine the impact of the phage on $\mathrm{Ca}$. Xc pathogenicity, it would of course have

344 been ideal to directly compare the phage-containing and uninfected pathogens. However,

345 currently this is not believed possible because classical inclusions are consistently accompanied

346 by phage-containing ones. This has been recorded in recent histology assessments from abalone

347 populations in Baja Mexico and Cayucos, San Nicolas Island, and Carmel California (Cruz-

348 Flores et al. 2016; Friedman et al. 2014a) and has been observed in abalone from Bodega Head

349 (CDFW unpublished observations). Consequently, we attempted to replicate a thermal induction

350 study undertaken with red abalone prior to appearance of the phage (Moore et al. 2000).

351 Comparing our results with those from that study strongly suggest that red abalone are better

352 able to withstand withering syndrome now than in years previous to phage presence. Anecdotal

353 observations from California red abalone farms support this conclusion (CDFW unpublished

354 observations).

355 However, these differences may be the result of other changes in the system, particularly as red

356 abalone have been challenged by the disease for nearly 30 years. For example, red abalone may

357 have developed heritable traits that confer immunity, as suggested by Brokordt et al (2017).

358 Alternatively, it is possible that $C a$. Xc may have evolved to become less pathogenic through any

359 number of mechanisms, including prophage; such a change cannot be elucidated by the

360 experimental design of this study and thus we cannot decipher those mechanisms or causations.

361 Recently, analysis of a subset of $C a$. Xc coding genes showed an absence of genetic variation

362 among samples taken from different geographic locations and from different abalone species;

363 suggesting that genetic variability in the bacterium may have a limited contribution to the 
364 differing pathogenic effects we observe in this system (Cicala et al. 2018). A genome wide

365 analysis might identify potentially attenuating virulence factors, which could be further

366 investigated for population variation as explored in the Cicala et al 2018 study; however, whole

367 genome sequence of $\mathrm{Ca}$. Xc has yet to be published.

368 In this study red abalone exposed to the $\mathrm{Ca}$. Xc showed no difference in body condition from

369 their control counterparts, suggesting the limited pathogenic effects of the current variant $\mathrm{Ca}$. Xc,

370 or at a minimum the WS expression was significantly delayed. This is in contrast to the white

371 abalone, for which we observed trends in body condition and survival that appear to be directly

372 related to $C a$. Xc gene copy numbers detected by qPCR. At the mid-point of the experiment,

373 coinciding with the highest mortality rate and lowest body condition index values, $\mathrm{Ca}$. Xc-

374 exposed white abalone in the elevated temperature group also showed the greatest bacterial

375 burden by qPCR. Despite any measured evidence in body shrinkage in the red groups, at the end

376 of the experiment, $\mathrm{Ca}$. Xc-exposed red abalone in the elevated temperature group had the highest

377 pathogen gene copy and after day 300, the $C a$. Xc-exposed, elevated temperature red group's

378 mortality rate appeared to increase; this might be indicative of disease expression after a nearly

379 yearlong incubation period. The high level of detection of $C a$. Xc DNA by tissue qPCR and

380 histological changes at the end of the experiment could be associated with this apparent increase

381 in mortality.

382 Our molecular data was supported by histological analysis. At day 343, $\mathrm{Ca}$. Xc inclusions were 383 only found in tissue samples from the two groups with the highest qPCR $\mathrm{Ca}$. Xc gene

384 amplification. Red abalone had a greater ratio of phage-containing inclusions to classical 385 inclusions. However, it is difficult to assess and isolate the impact of temperature and species on 386 our observations because we were only able to compare the red, elevated temperature group with 
387 the white, ambient group. While this study did not confirm phage particles by TEM, the highly-

388 recognizable granular, pleomorphic inclusions have consistently revealed observable phage

389 (Cruz-Flores \& Cáceres-Martínez 2016; Cruz-Flores et al. 2016; Friedman et al. 2014a). The

390 mottled, complex morphology of the phage-containing inclusions has been interpreted as

391 evidence of active phage-induced lysis (Friedman \& Crosson 2012). Inclusions with this

392 morphology were observed in our experimental white abalone; this study is the first to document

393 that white abalone are able to harbor the phage-containing variant of $\mathrm{Ca}$. Xc.

\section{CONCLUSION}

The results of this study have implications for restoration strategies to ultimately remove white abalone from the US Endangered Species list. The federal white abalone recovery plan concluded that outplanting of hatchery-produced animals must be the key restoration action for successful recovery of the species (Team 2008). White abalone in warm water appear highly susceptible to the current variant of $C a$. Xc, and outplanting efforts should take place in cooler water to minimize thermal enhancement of disease expression. The white abalone captive breeding program has recently introduced new wild-origin to its broodstock pool, which may increase genetic variation and render the progeny to be less sensitive to natural environmental stressors and possibly more resistant to the effects of $\mathrm{Ca}$. Xc. Studying heritable variation in susceptibility of white abalone families would be highly informative to the captive breeding efforts. In the Southern California Bight, cooler water typically translates to deeper water but also certain geographic locations with strong upwelling such as San Miguel Island (Erlandson et al. 2008). Our findings with red abalone align with the anecdotal reports from California abalone farmers that disease caused by $\mathrm{Ca}$. Xc has been much less frequent and severe since the phage has been observed. We conclude that the current form of $C a$. Xc, with its phage present, is 
410

411

412

414

415

416

417

418

419

420

421

422

423

424

425

426

427

428

429

430

431

432

433

434

435

436

437

438

439

associated with improved health and survival in red abalone under conditions that have

previously exacerbated the disease. However, the stability of this development is unknown.

Further investigation of the genome and the $C a$. Xc phage's phylogenetic relationships may shed

light on the some of the host-pathogen-phage interactions and provide an explanation for the observed effects associated with the current pathogen variant. Future efforts may be directed towards whole genome sequencing of $\mathrm{Ca}$. Xc and annotation of all mobile genetic elements of both the bacteria and the phage such that strains can be characterized and better understood to elucidate the mechanisms associated with pathogenicity in this important marine system.

\section{ACKNOWLEDGEMENTS}

We thank Chris Barker for statistical analysis of survival, Neil Willits for statistical consultation, and the White Abalone Recovery Project at the UC Davis Bodega Marine Laboratory for donating animals to this experiment.

\section{LITERATURE CITED}

Braid BA, Moore JD, Robbins TT, Hedrick RP, Tjeerdema RS, and Friedman CS. 2005. Health and survival of red abalone, Haliotis rufescens, under varying temperature, food supply, and exposure to the agent of withering syndrome. Journal of Invertebrate Pathology 89:219-231. 10.1016/j.jip.2005.06.004

Brokordt K, González R, Farías W, Winkler FE, and Lohrmann KB. 2017. First insight into the heritable variation of the resistance to infection with the bacteria causing the withering syndrome disease in Haliotis rufescens abalone. Journal of Invertebrate Pathology 150:15-20.

CDFGMR. 2005. Abalone Recovery and Management Plan. California Department of Fish and Game Marine Region.

Chambers MD, VanBlaricom G, Friedman CS, Hurn H, Garcelon D, and Schwemm C. 2005. Drift card simulation of larval dispersal from San Nicolas Island, CA, during black abalone spawning season. Proceedings of the Sixth California Islands Symposium: Institute for Wildlife Studies) Arcata, CA. p 421-434.

Chambers MD, VanBlaricom GR, Hauser L, Utter F, and Friedman CS. 2006. Genetic structure of black abalone (Haliotis cracherodii) populations in the California islands and central California coast: impacts of larval dispersal and decimation from withering syndrome. Journal of Experimental Marine Biology and Ecology 331:173-185. 
440

441

442

443

444

445

446

447

448

449

450

451

452

453

454

455

456

457

458

459

460

461

462

463

464

465

466

467

468

469

470

471

472

473

474

475

476

477

478

479

480

481

482

483

484

485

486

Cicala F, Cisterna-Céliz JA, Moore JD, and Rocha-Olivares A. 2017a. Structure, dynamics and predicted functional ecology of the gut microbiota of the blue (Haliotis fulgens) and yellow (H. corrugata) abalone from Baja California Sur, Mexico. PeerJ PrePrints.

Cicala F, Moore JD, Cáceres-Martínez J, Del Río-Portilla MA, Hernández-Rodríguez M, Vásquez-Yeomans R, and Rocha-Olivares A. 2017b. Multigenetic characterization of 'Candidatus Xenohaliotis californiensis'. International Journal of Systematic and Evolutionary Microbiology 67:42-49.

Cicala F, Moore JD, Cáceres-Martínez J, Del Río-Portilla MA, Hernández-Rodríguez M, Vásquez-Yeomans $\mathrm{R}$, and Rocha-Olivares A. 2018. Monomorphic pathogens: The case of Candidatus Xenohaliotis californiensis from abalone in California, USA and Baja California, Mexico. Journal of Invertebrate Pathology 154:19-23.

Connelly K, Horner-Devine MC, and Friedman C. 2012. Effects of Exposure to the Withering Syndrome Pathogen on the Gut Microbiome of Black Abalone from San Nicolas Island and Carmel, CA. Journal of Shellfish Research: Natl Shellfisheries Assoc C/O Dr. Sandra E. Shumway, Univ Connecticut, 1080 Shennecossett Rd, Groton, Ct 06340 USA. p 271-271.

Cook PA. 2016. Recent Trends in Worldwide Abalone Production. Journal of Shellfish Research 35:581583.

Crosson LM, Wight N, VanBlaricom GR, Kiryu I, Moore JD, and Friedman CS. 2014. Abalone withering syndrome: distribution, impacts, current diagnostic methods and new findings. Diseases of Aquatic Organisms 108:261-270. 10.3354/dao02713

Cruz-Flores R, and Cáceres-Martínez J. 2016. The hyperparasite of the rickettsiales-like prokaryote, Candidatus Xenohaliotis californiensis has morphological characteristics of a Siphoviridae (Caudovirales). Journal of Invertebrate Pathology 133:8-11.

Cruz-Flores R, Cáceres-Martínez J, Del Río-Portilla MÁ, Licea-Navarro AF, Gonzales-Sánchez R, and Guerrero A. 2018. Complete genome sequence of a phage hyperparasite of Candidatus Xenohaliotis californiensis (Rickettsiales) - a pathogen of Haliotis spp (Gasteropoda). Archives of virology 163:1101-1104. 10.1007/s00705-018-3703-3

Cruz-Flores R, Cáceres-Martínez J, Muñoz-Flores M, Vásquez-Yeomans R, Rodriguez MH, Del Río-Portilla MÁ, Rocha-Olivares A, and Castro-Longoria E. 2016. Hyperparasitism by the bacteriophage (Caudovirales) infecting Candidatus Xenohaliotis californiensis (Rickettsiales-like prokaryote) parasite of wild abalone Haliotis fulgens and Haliotis corrugata from the Peninsula of Baja California, Mexico. Journal of Invertebrate Pathology 140:58-67.

Friedman CS, Andree KB, Beauchamp K, Moore JD, Robbins TT, Shields JD, and Hedrick RP. 2000. 'Candidatus Xenohaliotis californiensis', a newly described pathogen of abalone, Haliotis spp., along the west coast of North America. International Journal of Systematic and Evolutionary Microbiology 50:847-855.

Friedman CS, and Crosson LM. 2012. Putative Phage Hyperparasite in the Rickettsial Pathogen of Abalone, "Candidatus Xenohaliotis californiensis". Microbial Ecology 64:1064-1072. 10.1007/s00248-012-0080-4

Friedman CS, Scott BB, Strenge RE, Vadopalas B, and McCormick TB. 2007. Oxytetracycline as a tool to manage and prevent losses of the endangered white abalone, Haliotis sorenseni, caused by withering syndrome. Journal of Shellfish Research 26:877-885.

Friedman CS, Wight N, Crosson LM, VanBlaricom GR, and Lafferty KD. 2014a. Reduced disease in black abalone following mass mortality: phage therapy and natural selection. Frontiers in microbiology 5:10. 10.3389/fmicb.2014.00078

Friedman CS, Wight N, Crosson LM, White SJ, and Strenge RM. 2014b. Validation of a quantitative PCR assay for detection and quantification of 'Candidatus Xenohaliotis californiensis'. Diseases of Aquatic Organisms 108:251-259. 10.3354/dao02720 
487

488

489

490

491

492

493

494

495

496

497

498

499

500

501

502

503

504

505

506

507

508

509

510

511

512

513

514

515

516

517

518

519

520

521

522

523

524

525

526

527

528

529

530

531

532

533

Gardner GR, Harshbarger JC, Lake JL, Sawyer TK, Price KL, Stephenson MD, Haaker PL, and Togstad HA. 1995. Association of prokaryotes with symptomatic appearance of withering syndrome in black abalone Haliotis cracherodii. Journal of Invertebrate Pathology 66:111-120.

González R, Lohrmann KB, Pizarro J, and Brokordt K. 2014. Differential susceptibility to the Withering Syndrome agent and renal coccidia in juvenile Haliotis rufescens, Haliotis discus hannai and the interspecific hybrid. Journal of Invertebrate Pathology 116:13-17.

Haaker P, Parker D, Togstad H, Richards D, Davis G, and Friedman C. 1992. Mass mortality and withering syndrome in black abalone, Haliotis cracherodii. California In: Shepherd SA, Tegner MJ, Gusman del Proo SA (eds) Abalone of the world: biology, fisheries and culture Proceedings of the first international symposium on abalone University Press, Cambridge. $p$ 214-224.

Harvell C, Kim K, Burkholder J, Colwell R, Epstein PR, Grimes D, Hofmann E, Lipp E, Osterhaus A, and Overstreet RM. 1999. Emerging marine diseases--climate links and anthropogenic factors. Science 285:1505-1510.

Leighton DL. 1972. Laboratory observations on the early growth of the abalone, Haliotis sorenseni, and the effect of temperature on larval development and settling success. Fish Bull 70:373-380.

León M, and Bastías R. 2015. Virulence reduction in bacteriophage resistant bacteria. Frontiers in microbiology 6:343.

Masui S, Kamoda S, Sasaki T, and Ishikawa H. 2000. Distribution and evolution of bacteriophage WO in Wolbachia, the endosymbiont causing sexual alterations in arthropods. Journal of molecular evolution 51:491-497.

Moore JD, Robbins TT, and Friedman CS. 2000. Withering syndrome in farmed red abalone Haliotis rufescens: thermal induction and association with a gastrointestinal Rickettsiales-like prokaryote. Journal of Aquatic Animal Health 12:26-34.

Moore JD, Robbins TT, Hedrick RP, and Friedman CS. 2001. Transmission of the Rickettsiales-like prokaryote "Candidatus xenohaliotis californiensis" and its role in Withering syndrome of California abalone, Haliotis spp. Journal of Shellfish Research 20:867-874.

Perez Sepulveda B, Redgwell T, Rihtman B, Pitt F, Scanlan DJ, and Millard A. 2016. Marine phage genomics: the tip of the iceberg. FEMS microbiology letters 363.

R Core Team. 2014. R: A Language and Environment for Statistical Computing. R Foundation for Statistical Computing. Vienna, Austria: R Foundation for Statistical Computing.

Rogers-Bennett L, Aquilino KM, Catton CA, Kawana SK, Walker BJ, Ashlock LW, Marshman BC, Moore JD, Taniguchi IK, and Gilardi KV. 2016. Implementing a restoration program for the endangered white abalone (Haliotis sorenseni) in California. Journal of Shellfish Research 35:611-618.

Rosenblum E, Viant M, Braid B, Moore J, Friedman C, and Tjeerdema R. 2005. Characterizing the metabolic actions of natural stresses in the California red abalone, Haliotis rufescens using $1 \mathrm{H}$ NMR metabolomics. Metabolomics 1:199-209.

Stierhoff KL, Neumann M, Mau SA, and Murfin DW. 2014. White abalone at San Clemente Island: population estimates and management recommendations. Technical Memorandum NMFS, NOAA. 1-16.

Team TWAR. 2008. Recovery Plan White Abalone (Haliotis sovenseni). National Marine Fisheries Service: National Oceanic and Atmospheric Administration, National Marine Fisheries Service, Office of Protected Resources

Tegner M, Dayton PK, Edwards PB, and Riser KL. 1996. Is there evidence for long-term climatic change in southern California kelp forests? California Cooperative Oceanic Fisheries Investigations Report:111-126.

Tegner MJ, Haaker PL, Riser KL, and Vilchis LI. 2001. Climate variability, kelp forests, and the southern California red abalone fishery. Journal of Shellfish Research 20:755-764. 
534 Vilchis LI, Tegner MJ, Moore JD, Friedman CS, Riser KL, Robbins TT, and Dayton PK. 2005. Ocean warming 535 effects on growth, reproduction, and survivorship of southern California abalone. Ecological $536 \quad$ Applications 15:469-480.

537 
Figure $\mathbf{1}$ (on next page)

Experimental set up: Experimental variables are illustrated as follows: (A) Candidatus Xenohaliotis californiensis (Ca. Xc) exposed, $18.5^{\circ} \mathrm{C}$; (B) Ca. Xc exposed, $13.6^{\circ} \mathrm{C}$; (C) Control, $18.5^{\circ} \mathrm{C}$.

Experimental units - tanks - are represented as cylinders; red or white fill represents those stocked with red or white abalone respectively. Elevated $\left(18.5^{\circ} \mathrm{C}\right)$ and ambient $\left(13.6^{\circ} \mathrm{C}\right)$ seawater flowed from header tanks holding infected or uninfected animals for the first 161 days to transmit $C a$. Xc. 
(A) Ca. Xc - Exposed

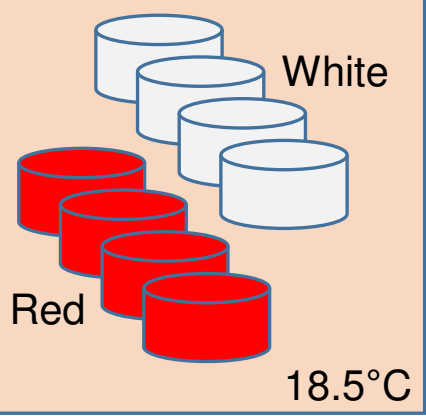

(B) Ca. Xc - Exposed

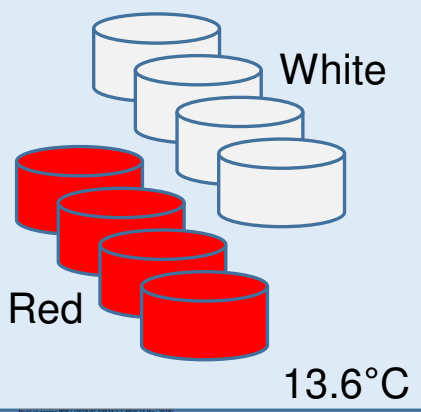

(C) Control

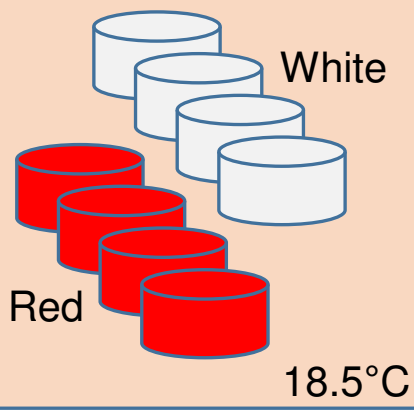


Figure 2 (on next page)

Percent survival of red and white abalone held in ambient water $\left(13.6^{\circ} \mathrm{C}\right)$ or at elevated temperature $\left(18.5^{\circ} \mathrm{C}\right)$ with and without Candidatus Xenohaliotis californiensis (Ca. XC) exposure for 343 days; $N=64$ for each group at day.

Each curve represents one of the six treatment groups, with variables: $\mathrm{Ca}$. Xc exposure, seawater temperature, and species. We observe a significant difference between survival curves of red and white abalone held under elevated seawater temperature and $\mathrm{Ca} . \mathrm{Xc}$ exposure conditions. 


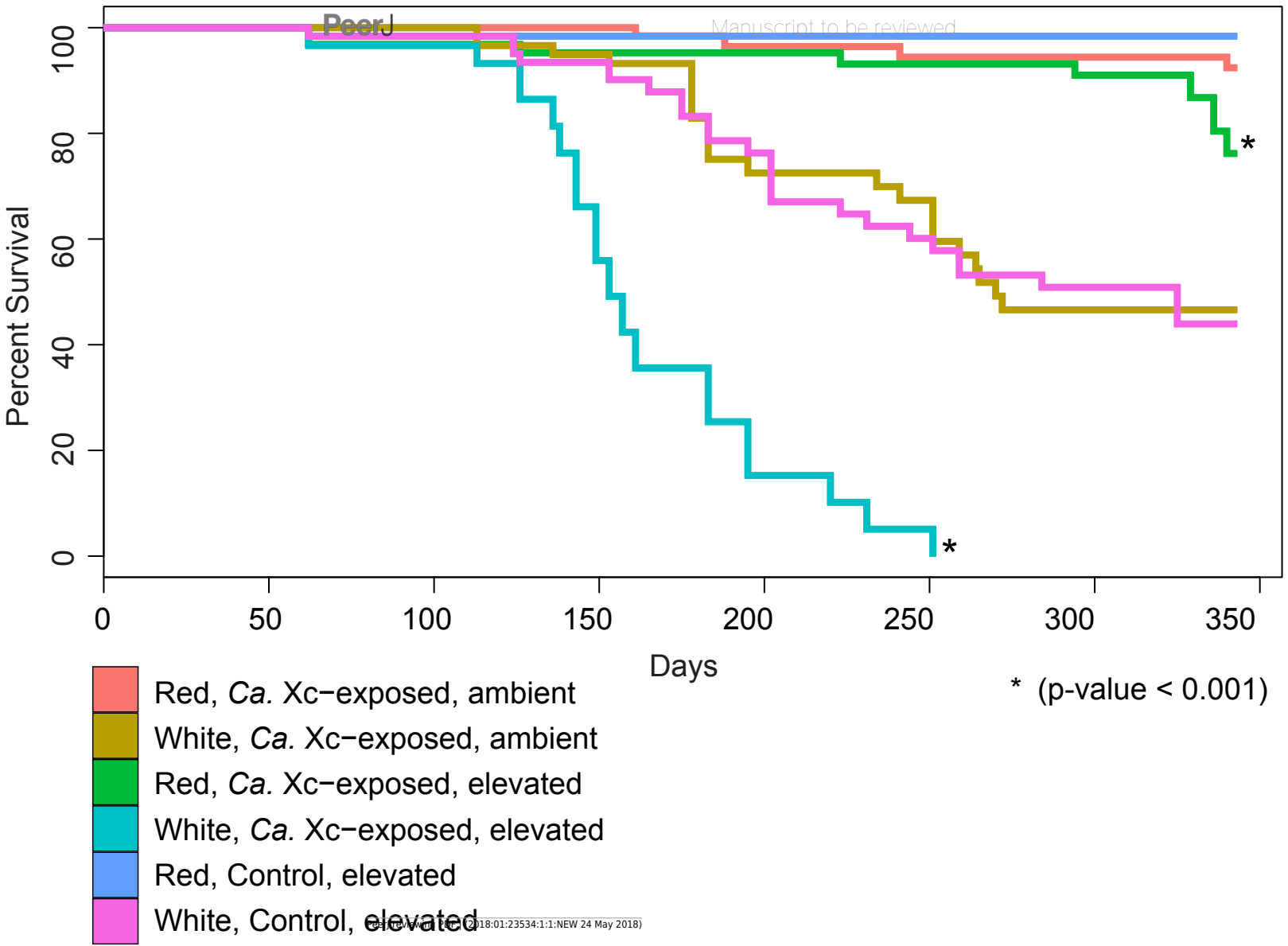




\section{Figure 3 (on next page)}

Longitudinal plot of mean values in Condition Index $(\mathrm{Cl})$, calculated by total abalone weight divided by shell length cubed, over time of experimental groups.

Error bars represent standard error of the mean. (a.) Initial $\mathrm{Cl}$ values of white abalone, destined for $\mathrm{Ca}$. Xc exposure were significantly greater than the other groups. (p-values < $0.05)$ (b.) $\mathrm{Cl}$ values of white, control abalone were significantly lower than red, control abalone ( $p$-value $=0.007)(c$.) $\mathrm{Cl}$ values of white, $\mathrm{Ca}$. Xc-exposed, ambient abalone were significantly lower than red, $\mathrm{Ca}$. Xc-exposed, ambient abalone ( $\mathrm{p}$-value $<0.001$ ) (d.) Cl values of white, $\mathrm{Ca}$. Xc-exposed, elevated abalone were significantly lower than red, Ca. Xcexposed, elevated abalone ( $p$-value $<0.001)(e$.) $\mathrm{Cl}$ values of white, control abalone were significantly lower than red, control abalone ( $p$-value $=0.007)(f$.$) Cl values of white, \mathrm{Ca}$. Xcexposed, ambient abalone were significantly lower than red, Ca. Xc-exposed, ambient abalone ( $p$-value $<0.001$ ) 
Figure 4 (on next page)

Log transformed qPCR-derived Candidatus Xenohaliotis californiensis gene copy numbers from PE tissue at days 161 and 343.

(a.) At day 161, no Ca. Xc genes amplified in the red, ambient group (b.) No Ca. Xc genes amplified in the control groups (c.) Prior to day 343, all abalone in the white, Ca. Xc- exposed, elevated group died. 


\section{Figure 5}

Candidatus Xenohaliotis californiensis inclusions within posterior esophagus epithelia from white abalone held at $18.5^{\circ} \mathrm{C}$ and $\mathrm{Ca}$. $\mathrm{Cx}$ exposed at 161 days.

Arrows indicate (A) classical inclusions, (B) Phage-containing variant inclusions. Haematoxylin and eosin. Bars, $50 \mu \mathrm{m}$.






\section{Table $\mathbf{1}$ (on next page)}

Presence or absence of Candidatus Xenohaliotis californiensis (Ca. Xc) DNA in feces from experimental groups between day 0 and 342 by qPCR.

DNA extracted from tank feces was pooled by group and time period for PCR. Presence is defined as mean $C a$. Xc gene copy number greater than or equal to three. *NA, no animals remain at this time period. 
1

\begin{tabular}{|l|c|c|c|}
\hline Group: species, treatment, temperature & \multicolumn{3}{|c|}{ Days } \\
\hline & $0-113$ & $126-236$ & $251-342$ \\
\hline Red, Ca. Xc-exposed, ambient & - & + & + \\
\hline White, Ca. Xc-exposed, ambient & + & + & + \\
\hline Red, Ca. Xc-exposed, elevated & + & + & + \\
\hline White, Ca. Xc-exposed, elevated & - & - & NA \\
\hline Red, control, elevated & - & - & - \\
\hline White, control, elevated & & & - \\
\hline
\end{tabular}

$2+$ greater or equal to 3 gene copies - less

3 than 3 gene copies 


\section{Table 2 (on next page)}

Comparison of cumulative mortality rates between a 2000 study and the current study of thermal induction of withering syndrome in red abalone. 
1

\begin{tabular}{|l|c|c|c|c|}
\hline & $\begin{array}{c}\text { Average Seawater } \\
\text { Temperature }\end{array}$ & $\mathrm{N}$ & $\begin{array}{c}\text { Cumulative mortality } \\
\text { events } \\
\text { at day }=220\end{array}$ & $\begin{array}{c}\text { Percent } \\
\text { survival }\end{array}$ \\
\hline Current study & 18.5 & 46 & 4 & $91 \%$ \\
\hline Moore et al. 2000 & 18.5 & 30 & 10 & $67 \%$ \\
\hline
\end{tabular}

2 


\section{Table 3(on next page)}

Histological analysis of Candidatus Xenohaliotis californiensis - inclusion type prevalence in post esophagus and digestive gland tissue samples by group at day 343 . 
2

\begin{tabular}{|l|l|l|l|l|l|l|}
\hline \multirow{2}{*}{$\begin{array}{l}\text { Species, treatment, } \\
\text { temperature condition }\end{array}$} & \multicolumn{3}{|l|}{ Post-esophagus } & \multicolumn{3}{|c|}{ Digestive gland } \\
\cline { 2 - 7 } & \multicolumn{2}{|c|}{ Inclusion type } & & \multicolumn{3}{|c|}{ Inclusion type $^{*}$} \\
\hline $\begin{array}{l}\text { Red, Ca. Xc-exposed, } \\
\text { ambient }\end{array}$ & 34 & $0 \%$ & $0 \%$ & 54 & $0 \%$ & $0 \%$ \\
\hline $\begin{array}{l}\text { White, Ca. Xc-exposed, } \\
\text { ambient }\end{array}$ & 14 & $29 \%$ & $14 \%$ & 19 & $0 \%$ & $0 \%$ \\
\hline $\begin{array}{l}\text { Red, Ca. Xc- } \\
\text { exposed, elevated }\end{array}$ & 35 & $89 \%$ & $77 \%$ & 46 & $20 \%$ & $15 \%$ \\
\hline $\begin{array}{l}\text { White, Ca. Xc-exposed, } \\
\text { elevated }\end{array}$ & 0 & NA & NA & 0 & NA & NA \\
\hline Red, control, elevated & 27 & $0 \%$ & $0 \%$ & 62 & $0 \%$ & $0 \%$ \\
\hline Red, control, elevated & 8 & $0 \%$ & $0 \%$ & 22 & $0 \%$ & $0 \%$ \\
\hline
\end{tabular}

